\title{
What makes a democratic people?
}

\author{
David Miller
}

Rainer Bauböck has offered us a fascinating and wide-ranging analysis of a question that is often now referred to as "the democratic boundary problem". ${ }^{1}$ How does this problem arise? Before we can begin to discuss how a democracy might function, what decision rules it should use, and so forth, we have to decide how it should be constituted. But on closer inspection, this turns out to raise two questions rather than one. The first is the question of jurisdiction: over what domain is the democratic body we are about to constitute authorized to take decisions? By a domain here I mean a geographical area - a territory - within which the decisions that the democracy is going to take will be applied. ${ }^{2}$ Then there is the question of inclusion: who will form part of the relevant demos that makes these decisions, in the sense of being eligible to vote in elections and referendums, stand for office, and so forth? These two questions are obviously intertwined. Indeed one might be tempted to think that by answering the jurisdiction question one has also found the answer to the inclusion question: the demos should be made up of all and only those who fall under the jurisdiction of the democratic unit we are about to create. But, as Bauböck's admirable discussion makes

1 This has already generated a substantial literature. See, for example, Whelan (1983); Arrhenius (2005); Song (2012); Saunders (2012); Erman (2014). My own contribution is Miller (2009).

2 Of course, the jurisdiction of a democratic body need not be territorially defined - for example a professional association or a trade union can have a democratic constitution. But here we are concerned with democratic institutions in the conventional political sense, and these always have territorial jurisdictions. 
abundantly clear, this is far too simple an answer. Both jurisdiction and inclusion pose intractable questions for democrats. Moreover, these questions are not just theoretical. The first arises in practice whenever one state annexes territory that previously belonged to another, altering jurisdictional boundaries, or when a region within a state secedes to form a state of its own. How, if at all, might such domain changes be justified? And the issue of inclusion arises whenever democracies have to decide who among the many people present on their territory at any moment should qualify for full rights of citizenship, as well as who among those currently outside the territory might also qualify.

How, then, should we think about these two interrelated boundary problems? Can the same principles guide us towards solutions to both, or do they have to be addressed independently? And which needs to be tackled first? You might think that jurisdiction is the more basic problem: we need to establish the size and the shape of the political unit that will be governed democratically before we can decide who should be entitled to take part in running it. We could, for instance, try to settle the domain question on functional grounds. Suppose our aim is to create a democratic state: then we should form a unit that is neither so small that it cannot carry out the basic functions of a state, whatever those turn out to be, nor so large that it becomes too unwieldy to be governed democratically. We might also appeal to geographical or economic grounds for choosing a particular jurisdictional space. Having sorted out which principles should apply to jurisdiction, we could then go on to tackle the inclusion issue, with at least a strong presumption that all those who fall within a democracy's jurisdictional domain should be included in the demos. However, we could also proceed quite differently. We could begin by asking: what must a group be like if it is to form an effective demos - one that can operate in the way that we hope a democratic body should? In asking this, we make the assumption that not just any randomly selected set of individuals could compose such a body; a collective that is able to work as a viable democracy must have certain essential features - the members must speak a common language or languages, for example. Then, having arrived at principles 
for constituting demoi, we would settle the jurisdiction question by drawing boundaries in such a way that as far as possible each set of boundaries enclosed a viable demos. If for some reason the As and Bs can't work together democratically, then we should try if we can to give each group their own area of jurisdiction, perhaps even their own state.

The discussion in the previous paragraph might create the impression that we have to solve the boundary problem starting from scratch, in a world where no boundaries yet exist, which is of course absurd. The point, however, is that we do face jurisdiction and inclusion problems in the world as it is, with boundaries already drawn, and then we have to decide in which direction to look for guidance. Suppose for instance we had to adjudicate between possible solutions to the Israel/Palestine problem. We might begin by addressing questions of jurisdiction first, and conclude that, for economic and other reasons, it makes sense to have a single state in the region now covered by the state of Israel and the occupied territories. Having settled that issue, we would move on to consider the composition of the citizen body who should govern it, as well as other questions concerning the institutional form that democracy should take in that area. Alternatively, we might take the composition of the demos as our most basic question, and ask whether Israelis and Palestinians together could form one. If the answer to that question turns out to be "No", then we would approach the jurisdiction issue on the assumption that two separate units - quite possibly two independent states existing side by side - need to be created. My point here is not to suggest that either the one-state or the two-state solution is necessarily to be preferred, but to illustrate how it makes a difference whether the question we first ask is about jurisdiction or about inclusion in the demos.

But where should we start? This will depend on how we understand democracy and the values that underlie it. Here we need to draw another distinction. Democracy, uncontroversially, is a way of making political decisions. But we can focus our attention either on the input side of any decision or series of decisions, or on the output side. That is, we can investigate how a decision came to be made, how good or bad 
the process was that led to that particular decision being reached; or we can investigate the impact that a decision will have on the people being affected by it, asking in particular whether the needs or interests of those people were properly taken into account when the decision was made. From a democratic perspective, both of these aspects should matter. Presumably we want democratic decision procedures to meet certain standards internally. We want the decisions that are reached to be mutually consistent, for example; we want them to be informed by the relevant evidence, where appropriate; we don't want majorities to ride roughshod over minorities within the demos. But we should be concerned about impact as well. Something has gone wrong if a democratic institution, no matter how well functioning internally, takes decisions that may inflict serious harms on people who are not represented in the body that decides. We cannot just assume that good procedures will always take proper account of the interests of those who have no say in the process itself: "no taxation without representation", as the old slogan has it. So both aspects are important, but how we weight them relative to one another may depend on our underlying conception of democracy, as I have argued elsewhere (Miller 2009).

Most of Bauböck's discussion addresses the impact side of this debate: he is trying mainly to pin down the kind of impact that will entitle its recipient to participate in a democratic body. I shall shortly be discussing the various answers to the impact question that he canvasses, but first we should observe that he is also sensitive to the issue of functioning. He recognizes that a viable demos must possess certain features, in particular a sufficient degree of stability. This emerges in the course of his very interesting discussion of mobile and sedentary societies. As he notes:

Democracy also needs a sense of "ownership" and belonging to the polity. It is difficult to imagine how hypermobile populations could be citizens of the territorial polity who authorize the government that issues and implements the laws to which they are subjected. If there is 
a relatively sedentary core population, then immigrants can integrate into the society while emigrants can remain connected to it across borders. Where there is no such core, it will be difficult to generate among territorial populations a sense of responsibility for the common good of the polity. (p. 17)

This is important, though I shall later argue that Bauböck does not pursue the idea to its logical conclusion. In particular it exposes for what it is the fantasy that democracy could work on an ad hoc basis, with different constituencies being assembled to decide each issue as it arose. So already we can see that attending to the process side of democracy will place some constraints on the possible answers one might give to the impact question. Solutions to the latter question that are incompatible with the thesis stated in the paragraph above ought to be summarily rejected.

Despite this, Bauböck begins by considering sympathetically the all affected interests (AAI) principle, according to which "all those whose interests are affected by any possible decision arising out of any possible agenda must be included in the demos" (p. 22). ${ }^{3}$ Taken literally, this would mean that the demos must be global in scope, since any decision taken by a less inclusive body is liable to affect the interests of at least some outsiders, and Bauböck recoils from this conclusion, arguing that democracy presupposes the existence of a plurality of bounded political communities. Nevertheless, he concedes to the defenders of AAI that "those whose interests are affected by a decision have a democratic claim that their interests be taken into account in the process of decisionmaking and implementation" (p. 20). It is not entirely clear what is needed to satisfy this claim: do the interests of outsiders have to be represented in some way when the decision is taken? There are moments at which this seems to be Bauböck's view. He says "actually affected interests have a claim to voice. They must be heard and taken into account by those

For debate about this principle, see Goodin (2007); Näsström (2011); Owen (2012); as well as the works cited in note 1 above. 
who take the decision" (p. 24). But this is immediately equated with having a "right to justification of the decision", which seems less to do with having a voice before the decision is made and more to do with the decision itself being such that once taken it can be justified to all those whose interests it affects - a substantive rather than procedural requirement.

Rather than trying to find a version of AAI that renders it consistent with the sedentarist thesis that democracy requires a bounded territory and a relatively stable core membership, it would be better simply to drop AAI altogether as a solution to the boundary problem. It is, after all, highly implausible in the canonical form cited in the previous paragraph. Consider an example. The British Chancellor decides to raise consumption taxes to finance rising health care costs. British consumers have a bit less disposable income and decide to cut back on Mediterranean holidays. This, obviously, has an impact on the livelihoods of the island-dwellers for whom tourism is the main source of income. Perhaps the marginal beach-bar owner will be forced out of business. Should he or she have a voice in the Chancellor's decision? Is the Chancellor even required to justify his decision to the bar owner? I take the answers to these questions to be obvious, but it may still be worth spelling out why. Anyone who sets up a beach-bar on a Greek island must expect that tourist flows will vary significantly from year to year and take appropriate precautions (save in the good years, have a second line of work for the bad years, etc.). They have entered a market, and markets are not only unpredictable in general but are also affected by government decisions (including foreign government decisions) over things like monetary policy and tax rates. Like human beings everywhere, beach-bar owners are responsible agents who need to protect themselves against decisions over which they neither have control in fact, nor are entitled to have it normatively. To have to justify ourselves to everyone whose interests we might affect by our actions would make it impossible for people to act at all, except in the rare cases where what we do is fully selfregarding - that is, has no perceptible impact on anyone other than the agent herself. 
Defenders of AAI will protest that I have caricatured their principle by taking a case like the Mediterranean beach-bars. They are concerned with much weightier instances in which governments take decisions that impact outsiders - refugees, climate change, nuclear waste, and so forth. What this reveals, however, is that any plausible claims that might be advanced under AAI are better understood as falling under a Global Harm Principle (GHP), which among other things prohibits countries from causing serious and unavoidable harm to those outside their borders. ${ }^{4}$ In contrast to AAI, GHP only considers as relevant cases where interests are affected negatively, cases where the setback to interests is serious and cases where the setback cannot reasonably be avoided by prudent action on the affected agent's part. Where it is likely that a decision will be taken that breaches GHP, there may often be good reason to listen to the voices of those who are liable to be harmed, since they will be best placed to explain how the harm can be averted, or, if that is not possible, compensated for. So there are occasions when people outside of the demos do have a right to be heard by those inside Bauböck's conclusion is correct, but the principle that delivers it is GHP, not the wildly over-inflated AAI.

Let me turn, then, to the second principle of inclusion that Bauböck considers sympathetically (but ultimately rejects, at least as a comprehensive solution): the principle that all subject to coercion (ASC) by a democratic institution are entitled to participate in that institution. What does it mean to be subject to coercion? As Bauböck's discussion makes clear, he is thinking primarily of the case in which someone is governed by a legal system that uses coercive sanctions, not of isolated acts of coercion. This distinction is important. What lends plausibility to ASC is the thought that a coercively enforced legal system shapes people's lives in a fundamental way, and potentially exposes them to domination. To guard against this possibility, they must be given the opportunity to control how that system operates. The principle does

For defences of this principle, including discussion of how "harm" should be understood in a global context, see Linklater (2006) and Vernon (2010: ch. 7). 
not imply that whenever anyone is subjected to coercive force, they are entitled to a democratic say in how that force is exercised - a position that quickly reveals its absurdity. ${ }^{5}$

ASC tells us why everyone who is permanently resident in a country and subject to its government ought to be included as an equal participant in democratic institutions. Does it over-extend democratic rights by demanding that every immigrant who intends to stay must be granted full rights of citizenship immediately? Here we see why, in thinking about the democratic boundary problem, it is important to keep both the question of impact and the question of how democratic procedures are likely to operate in full view. When democracies require a period of some years of residence to elapse before immigrants can apply for citizenship, they do so (presumably) on the basis that new arrivals need to learn something about the politics of the country they are joining before they are given the responsibility of casting their votes. No doubt some will be prepared for this sooner than others, but a uniform residence requirement operates in the same way as a uniform age requirement for voting - as a rough indicator of when somebody is likely to be sufficiently competent to perform as a citizen in a democracy. So ASC can't be treated as providing necessary and sufficient conditions for inclusion; it needs to be used in conjunction with other principles, such as the presumptive competence principle just sketched. Nevertheless it carries a good deal of the weight, and in particular, as Bauböck emphasizes in the later stages of his essay, provides the best rationale for giving everyone who is resident in a local community voting rights in that community, regardless of their citizenship status.

What guidance can ASC provide in the case of those who are not resident in the relevant jurisdiction? As Bauböck says, it awards rights

\footnotetext{
"Imagine, for instance, that Ben and Jerry knock on my door and ask to enter my house, eat the dinner I was in the process of preparing, and then have sex with me ... I brandish a pistol and warn them that I will not hesitate to shoot if either of them puts so much as one foot inside my house ... Could Ben and Jerry rightfully object that, insofar as they were subjected to coercion, they were entitled to an equal vote as to what my decision should have been? Presumably not ..." (C. Wellman in Wellman and Cole 2011: 97).
} 
to those who are temporarily abroad but expected to return (since their lives overall will be shaped by the policies of the home government), but not to those who have emigrated on a permanent basis: if they are allowed to remain citizens with the right to vote, it must be on some other basis. Somewhat mysteriously, he also claims that ASC will grant rights to "coerced emigrants who have been driven into exile by a non-democratic predecessor regime. In these cases, the situation of individuals is comprehensively marked by subjection to coercion that they have experienced in the past and this creates an ongoing duty of protecting their rights" (p. 31). What is the argument here? People in this position will have a choice, under the current democratic regime, either to return home or to remain in the countries in which they have been exiled. If, despite the offer of readmission, they choose to stay where they are, then ASC grants them rights in that jurisdiction, since those are the laws that now and in the future will shape their lives. How can the fact of past coercion by country A - the forces that drove them into exile - justify A awarding them rights of participation in the present? ${ }^{6}$ ASC is restrictive towards those who do not currently fall within a government's jurisdiction, and this seems correct.

There is controversy, however, about the case of immigrants who are refused entry under the prevailing immigration policy. Is this an exercise of coercive jurisdiction, and does that mean that prospective immigrants are entitled to a say in the formulation of immigration law, if not over other issues? This position has been defended by Arash Abizadeh especially, though the claim about the coercive nature of immigration law has been widely accepted (Abizadeh 2008). ${ }^{7}$ I have

\footnotetext{
Perhaps the thought is that the present regime has inherited from its predecessor a special responsibility towards the exiles. It is not clear, however, why this would not be discharged by an offer of return, on favourable terms and with instant access to citizenship. Governments do also acknowledge a continuing responsibility towards their émigrés, in cases where the émigrés suffer bad treatment in the countries to which they have moved, but this seems to apply regardless of the reasons for emigration, and is not usually thought to justify extending voting rights.

Among others who claim that border controls are coercive are Carens (2013: ch. 12), Blake (2013) and Hidalgo (2014).
} 
subjected it to critique elsewhere (Miller 2010; 2016: ch. 4). In brief, I suggest (a) that not all coercive interventions give rise to democratic rights (see note 6 above); and (b) in the case of immigration policy, it is important to distinguish between the policy itself being coercive, and coercive means being used to enforce it. When people are prevented from entering a country by immigration controls, a significant opportunity is often being denied them, but it does not follow that their lives are being shaped and potentially dominated by the legal system of the country they are trying to enter in the same way as those who are already living under that system. So why should exclusion per se, independently of the means used to enforce it, be regarded as coercive?

Without signing up to the Abizadeh position, Bauböck wants nonetheless to say that the relationship between the state and at least some of those who want to immigrate can be described as coercive. However, the argument at this point morphs into the somewhat different thesis that states have a special responsibility to protect migrants "who have stronger claims to admission to this country than anywhere else" (p. 36). He does not elaborate on how such special claims are established, but let's assume that the migrant is someone who applies to state $S$ for asylum, or simply washes up on its shores. I agree that physical presence of this kind does give state $S$ a special responsibility to protect the migrant's rights, and in some cases this would mean granting her admission. But the argument here has nothing to do with coercion. What gives the migrant a claim is her specific vulnerability to $\mathrm{S}$, not the fact that $S$ is coercing her. So it is hard to see how ASC can be applied to such a case.

The limitations of ASC as a general solution to the democratic boundary problem, however, are best brought out by considering a case touched on briefly by Bauböck, one in which what is effectively a colony is incorporated into the metropolitan state in such a way that its inhabitants are given voting rights as citizens of that state. The example he cites is Algeria prior to independence in 1962, but one could also instance Ireland during the nineteenth century, when its voters sent MPs to Westminster. If we assume (contrary to fact) that every adult 
member of those territories had been awarded voting rights, then ASC would have been fully satisfied. As Bauböck says, the lesson here is that "a democratic principle of membership must link individual inclusion claims to collective self-government claims in order to avoid a status quo bias" (p. 30). But to do that we need some prior way of identifying Algeria and Ireland (rather than Algeria-in-France and Ireland-in-Britain) as the proper units of self-government, and ASC, as a principle of individual inclusion, is of no help here.

So what does Bauböck suggest instead? He proposes the all citizen stakeholder (ACS) principle as the main plank of his theory of democratic inclusion, with AAI and ASC both relegated to supporting roles. The best succinct statement of ACS is found in another of his papers: "Those and only those individuals have a claim to membership whose individual autonomy and well-being is linked to the collective self-government and flourishing of a particular polity" (Bauböck 2015: 825). ${ }^{8}$ Since this principle is presented as having the capacity to solve problems that neither AAI nor ASC can deal with adequately, we can assume that it is intended to provide an account of democratic membership that explains both why it would be wrong to deny voting rights to, say, women in Britain and why it would be wrong to re-annexe Ireland and govern it as a region of Britain. In other words, it can provide answers to questions of both inclusion and jurisdiction as I identified them at the outset. So it must be read so as to mean not merely that individuals have a claim to membership in whatever polity happens to govern them at any moment, but to membership in a polity that enables them to "link" their own autonomy and well-being to the collective autonomy of the polity as a whole. Bauböck's answer to the Algeria question will need to show that Algeria-in-France did not qualify as a polity of that sort; ACS would require Algeria to be both independent and democratic.

Moreover, this has to be demonstrated without recourse to two positions that Bauböck explicitly rejects: nationalism and voluntarism. He

I find this version more helpful than the slightly different formulation on p. 49 of the present essay. 
cannot, in other words, reject Algeria-in-France on the ground that Algeria forms a nation separate from France, and is entitled on that ground to self-government, or on the grounds that the inhabitants of Algeria had never consented to being governed by France. As he puts it, "political legitimacy in a democratic polity is not derived from nationhood or voluntary association but from popular self-government, that is, citizens' participation and representation in democratic institutions that track their collective will and common good" (p. 41).

I shall return later to Bauböck's rejection of nationhood as a basis for jurisdiction, but first I want to try to unpack these formulations of ACS. What kind of link is being postulated here between "individual autonomy and well-being" and "the collective self-government and flourishing" of the polity? Let me explore two possible answers. According to the first, the link in question is utilitarian. Individuals' interests will only be properly protected when they enjoy collective self-government with appropriate jurisdiction. This answer has some plausibility if we look at the examples I have been using. Britain and France governed Ireland and Algeria, respectively, less well than they might have been governed by institutions that were closer to the people and better informed about local conditions. But how far does it generalize? Can we be confident that when larger units break into two or more pieces, the new units always do a better job of protecting "individual autonomy and well-being" than their more inclusive predecessors? Do Slovaks enjoy more of these goods now than they did when Czechoslovakia was still intact? Or should we conclude that there was no sound case for that state to dissolve? If we acknowledge that it is sometimes legitimate for jurisdictional boundaries to be redrawn so that they align better with the physical habitation of a distinct "people", then the utilitarian way of reading Bauböck's link won't deliver that verdict.

The other possibility is that the link between individual and collective should be understood as psychological. People won't have a sense that they are free and flourishing unless they can identify with their government and see their own freedom as dependent upon the collective freedom of the people. This psychology seems to be what fuels many 
independence movements, for example. But if ACS understood in this way is also to serve as a principle for deciding upon individuals' rights to be included in the demos, it will yield some paradoxical results. Bauböck himself gives a relevant example, though I shall challenge his use of it. Consider a closed monastic order whose members have little interest in what is going on in the secular world beyond the cloister walls except so far as it interferes with their chosen way of life. Their overwhelming interest is in being left alone by the state. Bauböck claims that "even the members of reclusive monastic orders will be better off as citizens of a democratic polity than as stateless persons or as subjects of autocratic rule" (p. 41). But if this is indeed true - and there is certainly some reason to doubt it - it is not because the monks see any intrinsic value in belonging to a "self-governing political community". They do not connect their own flourishing, and the autonomy and flourishing of their religious community, with any wider version of collective self-government. Any benefits that come to them from inhabiting a democracy are purely instrumental. Do they therefore fail to qualify as "citizen stakeholders" and might they be excluded from voting rights under ACS? Or for a different example, consider those members of the cosmopolitan elite who are rich enough that swapping jurisdictions would at most be a mild inconvenience for them. They have no emotional or other psychological stake in the flourishing of any particular political community (so long as they can get their money out if it collapses). Should they too be disenfranchised under ACS?

This argument can be run in the other direction as well. Consider a passionate Francophile who lives outside of that jurisdiction and cannot for legal or practical reasons move to the country she adores. Nevertheless she follows the news avidly, celebrates when the French team triumphs on the football field and is deeply disturbed by events such as the Charlie Hebdo massacre. She seems to fall within the scope of the ACS principle as laid out above. But we might be unconvinced that such a psychological link, however strong, should be a qualification for rights of citizenship. Now in all these cases it would be possible to bite the bullet, and argue for enfranchising the non-resident Francophile and disenfranchising 
the monks and the disengaged sports stars and finance capitalists. But unless Bauböck is prepared to accept this, the psychological reading of the link postulated in ACS must be abandoned.

Perhaps there is some third way of reading ACS, and the connected idea of a "citizen stakeholder", that would yield plausible answers both to the jurisdiction question and to the inclusion question. But until this is provided, our verdict must be that there is no single principle that will do the job. Indeed Bauböck reaches a similar conclusion at the end of his essay, arguing that AAI, ASC and ACS all have some contribution to make to the general inclusion question, with different rights going to different constituencies in accordance with the demands of each principle. But if a pluralist approach to democratic legitimacy is correct, this opens the door to a reassessment of the nationalist principle that Bauböck firmly rejects, since we no longer expect that, or any other principle, to be doing all the work that needs to be done. So I should like to end these comments by reflecting on nationality as a source of democratic legitimacy, in the light of Bauböck's critique.

Bauböck concedes that his position resembles liberal nationalism in treating membership in a political community as prior to subjection to government and its decisions. But he argues that a nationalist principle of inclusion will be unable to deal satisfactorily with immigrants and other minority groups, since it requires that "admitting new members to the political community must serve the purpose of nation-building" (p. 39). Depending on the circumstances, this might mean selecting immigrants on cultural grounds, or closing the borders altogether. Now it is true that liberal nationalists will want immigration policy to be shaped in part by a concern for the preservation of national cultures, and this is likely to mean imposing restrictions on the numbers who enter, as well as pursuing active integration policies that seek to familiarize new arrivals with the culture and institutions of the country they are joining. But to say that immigration must "serve the purpose of nationbuilding" is an exaggeration; immigration policy must be compatible with nation-building, a much weaker condition. Moreover, liberal nationalists regard national culture as sufficiently flexible that it can 
accommodate the distinctive cultural contributions of national minorities and immigrants. The nation that is in the process of being built can be inclusive of these groups.

Bauböck is not committed to an open borders principle; nor does he say that we should judge principles of inclusion only according to the numbers of people who will be let in by following them. If following principle A has the consequence that fewer immigrants are admitted but those who are let in are better integrated, while following principle $\mathrm{B}$ would admit more but integrate them less well, is it obvious that $\mathrm{B}$ is to be preferred to $A$ ?

When it comes to national minorities, ACS is said to be sensitive to their claims. Democratic legitimacy may require that the state be defined constitutionally as "plurinational", and these minorities granted territorial autonomy. Where these conditions are not met, Bauböck says, internal minorities "have remedial rights to self-determination that may result in the formation of autonomous territories or new independent states" (p. 43). So it seems that, after all, he is committed to a principle of national self-determination, albeit not necessarily one requiring that the nation should control a state of its own. A national minority is something more than just a territorially concentrated population. Although he does not spell it out, Bauböck must assume that it has a political identity of its own that demands constitutional recognition and political arrangements through which it can exercise collective autonomy. But it is inconsistent to claim this for national minorities without recognizing that the same must hold for majority nations. What is true of the Basques and the Welsh must also be true of the Spanish and the British: a legitimate government for these peoples must be one that grants them an adequate measure of self-determination. ${ }^{9}$

In a footnote, Bauböck claims that he endorses secession only as a remedial measure, and denies that there can be "a primary right to self-determination". But there is something quite puzzling about this. How can self-determination be claimed as a remedy unless the group in question has a right to self-determination that had previously been violated? It would be rather like saying that I have no primary right to own property, but I do have a remedial right to take back stolen possessions. 
So long as it is applied flexibly, the nationality principle provides good answers to questions of jurisdiction and boundary-drawing. This is true even in cases where people's political identities are complex, and the jurisdictional solution needs to mirror this complexity, allowing for minorities within minorities and so forth. ${ }^{10}$ It is less successful as a principle of individual inclusion: it is not acceptable on democratic grounds to make citizenship rights dependent upon a person's national identity - though it is acceptable, I believe, to forge links between the two by means of citizenship education for native-born and immigrants alike, whose purpose is in part to encourage recipients to identify with the nation. It needs, therefore, to be used in conjunction with a principle such as ASC which grants citizenship rights to everyone who is permanently resident in a society, and thereby subject to the life-shaping effects of a coercive legal system. But whereas ASC by itself has nothing to say about the conditions for an effective democracy, other than that everyone who lives under it must be given the vote, the nationality principle underlines the role of a shared identity in creating social and political trust, thereby facilitating the accommodations and compromises that are essential if democratic decisions are to be accepted as authoritative by all concerned.

Earlier in the essay I cited, approvingly, a passage from Bauböck in which he argues that democracy requires a "core" population who are sedentary and think of themselves as "owning" the polity. They will acknowledge "duties of solidarity" towards one another and have "a sense of responsibility for the common good of the polity". To meet these conditions, however, it is clearly not enough for people simply to coexist side by side over time, since otherwise we would not witness conflict-ridden societies where near-neighbours are unable to cooperate to build a life together. The missing element, clearly, is that the people in question identify with one another as compatriots, recognize a common inheritance which may involve responsibilities as well as 
rights, and feel an obligation to their successors to leave the society in at least as good a shape as they found it. If we accept this - and I think Bauböck does - then the main issue is the kind of identity that is needed to perform this role. In the real world, the answer at least for the liberal democracies is nationhood, but it is a legitimate topic for research how far existing national identities can be "thinned" so that they become more accessible to newcomers. My own reading of the evidence is that we may face a tradeoff between thicker and more motivationally powerful forms of national identity and thinner and weaker, but more inclusive, forms (Miller and Ali 2014). Whatever the right answer, however, questions about identity are unavoidable, and this it seems to me is the missing ingredient in Bauböck's otherwise compelling discussion of democratic legitimacy.

\section{References}

Abizadeh, Arash 2008. "Democratic Theory and Border Coercion: No Right to Unilaterally Control Your Own Borders." Political Theory 36: 37-65.

Arrhenius, Gustaf. 2005. “The Boundary Problem in Democratic Theory." In (ed.), Democracy Unbound, edited by Folke Tersman. Stockholm: Stockholm University: 14-29.

Bauböck, Rainer 2015. "Morphing the Demos into the Right Shape: Normative Principles for Enfranchising Resident Aliens and Expatriate Citizens." Democratization 22: 820-839.

Blake, Michael 2013. "Immigration, Jurisdiction, and Exclusion", Philosophy and Public Affairs 41: 103-130.

Carens, Joseph 2013. The Ethics of Immigration. Oxford: Oxford University Press. Erman, Eva 2014. "The Boundary Problem and the Ideal of Democracy." Constellations 21: 535-546.

Goodin, Robert 2007. "Enfranchising All Affected Interests, and Its Alternatives." Philosophy and Public Affairs 35: 40-68.

Hidalgo, Javier 2014. "Freedom, Immigration, and Adequate Options." Critical Review of International Social and Political Philosophy 17: 212-234. 
Linklater, Andrew 2006. “The Harm Principle and Global Ethics.” Global Society 20: $329-343$.

Miller, David 2009. “Democracy's Domain." Philosophy and Public Affairs 37: 201-228.

Miller, David 2010. "Why Immigration Controls are not Coercive: A Reply to Arash Abizadeh." Political Theory 38: 111-120.

Miller, David 2014. “Debatable Lands." International Theory 6: 104-121.

Miller, David 2016. Strangers in Our Midst: The Political Philosophy of Immigration. Cambridge, MA: Harvard University Press.

Miller David and Sundas Ali. 2014. “Testing the National Identity Argument.” European Political Science Review 6: 237-259.

Näsström, Sofia 2011. “The Challenge of the All-Affected Principle.” Political Studies 59: 116-134.

Owen, David 2012. "Constituting the Polity, Constituting the Demos: On the Place of the All Affected Interests Principle in Democratic Theory and in Resolving the Democratic Boundary Problem.” Ethics and Global Politics 5: 129-152.

Saunders, Ben 2012. "Defining the Demos." Politics, Philosophy and Economics 11: $280-301$.

Song, Sarah 2012. "The Boundary Problem in Democratic Theory: Why the Demos should be Bounded by the State." International Theory 4: 39-68.

Vernon, Richard 2010. Cosmopolitan Regard: Political Membership and Global Justice. Cambridge: Cambridge University Press.

Wellman, Christopher and Phillip Cole. 2011. Debating the Ethics of Immigration: Is There a Right to Exclude? Oxford: Oxford University Press.

Whelan, Frederick 1983. "Prologue: Democratic Theory and the Boundary Problem." In NOMOS 25: Liberal Democracy, edited by J. Roland Pennock and John W. Chapman. New York: New York University: 13-47. 